\title{
HUBUNGAN ANTARA MOTIVASI MENJADI GURU DENGAN NILAI KETERAMPILAN MENGAJAR MAHASISWA PKM \\ ${ }^{1}$ Lisdewi Martini, ${ }^{2}$ Soeprijanto, ${ }^{3}$ Faried Wadjdi \\ 1,2,3 Pendidikan Teknik Elektro, Fakultas Teknik, Universitas Negeri Jakarta \\ 1,2,3 Email: lisdwm@gmail.com ; soeprijanto@unj.ac.id ; faried@unj.ac.id
}

\begin{abstract}
This research aims to determine of the relationship between motivation being a teacher and the value of PKM students teaching skills. In this research using quantitative approach with descriptive-correlative method. The population and sample in this research is the students in Electrical Engineering Department, Faculty of Engineering, State University of Jakarta. The technique of data collection is hypothesis test, $t$-test with previously performed prerequisite analysis test: normality test and linearity test.The calculation results shows that hypothesis test with significance level of 5\% obtained $r_{\text {count }}=0,4685$ and $r_{\text {table }}=0,230 r_{\text {calculated }}>r_{\text {table }}$ then the value that of $t_{\text {calculated }}=4,04652$ and $t_{\text {tabel }}=1,998$ which $t_{\text {calculated }}>t_{\text {tabel }}$ then its shows that there is positive and significant relationship between motivation being a teacher and the value of PKM students teaching skills. This research contributes to the world of education about the relationship between motivation being a teacher and the value of PKM students teaching skills and being a reference material for the next research, so the learning that gives is able to encourage or increase motivation being a teacher for students.
\end{abstract}

Keywords : Motivation being a teacher, PKM, Electrical Engineering Department.

\begin{abstract}
Abstrak
Penelitian ini bertujuan untuk mengetahui hubungan antara motivasi menjadi guru dengan nilai keterampilan mengajar mahasiswa PKM. Pada penelitian ini menggunakan pendekatan kuantitatif dengan metode deskriptif korelatif. Populasi dan sampel dalam penelitian adalah mahasiswa Program Studi Teknik Elektro Fakultas Teknik Univeristas Negeri Jakarta. Teknik analisis data yang digunakan adalah uji hipotesis dan uji-t yang sebelumnya dilakukan uji prasyarat analisis menggunakan uji normalitas dan uji linieritas. Hasil penelitian menunjukan bahwa uji hipotesis dengan taraf signifikansi $5 \%$ diperoleh nilai $\mathrm{r}_{\text {hitung }}=0,4685$ dan nilai $\mathrm{r}_{\text {tabel }}=0,230$, kemudian nilai $\mathrm{t}_{\text {hitung }}$ sebesar $=4,04652$ dan nilai $\mathrm{t}_{\text {tabel }}$ sebesar $=1,998$ dimana $\mathrm{t}_{\text {hitung }}>\mathrm{t}_{\text {tabel }}$ maka menunjukan terdapat hubungan yang positif dan signifikan antara motivasi menjadi guru dengan nilai keterampilan mengajar mahasiswa PKM. Penelitiam ini memberikan kontribusi pada dunia pendidikan mengenai hubungan antara motivasi menjadi guru dengan nilai keterampilan mengajar mahasiswa PKM dan menjadi bahan referensi untuk penelitian selanjutnya, sehingga pembelajaran yang diberikan mampu mendorong atau meningkatkan motivasi menjadi guru pada mahasiswa.
\end{abstract}

Kata kunci : Motivasi menjadi Guru, PKM, Pendidikan Teknik Elektro

\section{PENDAHULUAN}

Dalam peningkatan sumber daya manusia tidak lepas dari bagaimana pendidikan yang diperoleh, dimana untuk meningkatkan kualitas sumber daya manusia dapat melalui program pendidikan. Untuk menciptakan pendidikan indonesia yang berkualitas maka diperlukan tenaga pendidik atau guru yang profesional dan berkompeten dalam bidangnya. Karena dalam proses pembelajaran di sekolah seorang guru sangat berperan penting sebagai pendidik, pembimbing, penasihat, pendorong, dan teladan untuk siswa, maka dari itu mahasiswa khususnya mahasiswa keguruan dipersiapkan untuk memberikan perubahan pada pendidikan di indonesia.

Menurut isi pasal 10 ayat 1 Undang-Undang Republik Indonesia No. 14 Tahun 2005 tentang Guru dan Dosen, tugas utama guru adalah mendidik, mengajar, membimbing, mengarahkan, melatih, menilai, dan mengevaluasi peserta didik pada pendidikan anak usia dini, jalur pendidikan formal, pendidikan dasar, dan pendidikan menengah. Tenaga pendidik merupakan suatu komponen penting dalam menyelenggarakan proses pembelajaran. Dalam menjalankan profesi sebagai seorang pendidik harus mempunyai bekal dengan keterampilan-keterampilan dasar mengajar.

Sejalan dengan itu, Universitas Negeri Jakarta termasuk dalam Lembaga Pendidikan Tenaga Kependidikan (LPTK) dimana sebagian besar lulusannya menjadi sarjana pendidikan dan menjadi tenaga pendidik profesional yang menguasai pengetahuan dan kemampuan dalam menyelenggarakan pembelajaran. Pada dasarnya mahasiswa telah mendapatkan bekal kemampuannya dalam melaksanakan pembelajaran melalui perkuliahan dan 
praktik agar mahasiswa siap untuk mengaplikasikan ilmu selama perkuliahan dan tidak merasa kaku dihadapan peserta didik.

Salah satu program studi yang meluluskan mahasiswa sebagai sarjana pendidikan yaitu Program studi Pendidikan Teknik Elektro Fakultas Teknik Universitas Negeri Jakarta. Dalam masa perkuliahan mahasiswa Pendidikan Teknik Elektro yang disiapkan menjadi calon pendidik sudah dipersiapkan dari awal semester untuk memiliki kompetensi seorang guru dengan diberikannya Mata Kuliah Umum (MKU), Mata Kuliah Dasar Kependidikan (MKDK), Mata Kuliah Bidang Keahlian dan Penunjang (MKBKP), dan Mata Kuliah Keterampilan Proses Pembelajaran (MKKPP). Sehingga diharapakan setelah menempuh mata kuliah kependidikan mahasiswa menjadi guru yang profesional.

Pada keadaan di lapangan mahasiswa yang masuk ke dalam Program studi Pendidikan Teknik Elektro tidak semuanya memiliki citacita menjadi seorang guru, sehingga mahasiswa yang melaksanakan perkuliahan memiliki motivasi yang berbeda-beda. Motivasi adalah sebagai pendorong usaha dalam diri untuk pencapaian prestasi atau tujuan. Motivasi terbagi menjadi dua yaitu intrinsik dan ektrinsik dimana, mahasiswa yang termotivasi secara intrinsik akan merasa senang dalam melakukan hal yang berhubungan dengan keguruan dan menjadikannya sebuah kebutuhan. Namun, mahasiwa yang termotivasi secara ektrinsik melakukan aktivitas hanya sebagai sarana mencapai tujuan atau memenuhi kewajiban. Maka tidak semua mahasiswa mempunyai motivasi menjadi guru dalam dirinya.

PKM adalah kegiatan praktik mengajar terpadu yang terdiri atas aspek-aspek merencanakan, mengorganisasikan, melaksanakan, memantau, mengendalikan dan membina segenap daya agar tujuan program keterampilan mengajar di lapangan dapat tercapai. Sebagai calon sarjana keguruan mahasiswa akan melaksanakan program PKM, dimana mengharuskan mahasiswa menjadi seorang guru yang mampu melaksanakan tugas dan fungsinya yaitu memiliki keterampilan mengajar. Keterampilan mengajar (teaching skills) adalah kemampuan atau keterampilan yang bersifat khusus (most specific instructional behaviours) yang harus dimiliki oleh guru, dosen, instruktur, atau widyaiswara agar dapat melaksanakan tugas mengajar secara efektif, efisien dan profesional.

Keterampilan mengajar guru merupakan suatu hal yang penting dalam proses pembelajaran karena seorang guru mampu menumbuhkan gairah belajar peserta didik adalah dengan menggunakan keterampilan mengajar, hal ini sejalan dengan pendapatnya Suparman (2010: 59) bahwa keterampilan dalam mengajar menjadi syarat mutlak untuk efektifnya sebuah proses pembelajaran. Menurut Kusnadi (2008: 45) keterampilan mengajar adalah kemampuan yang dimiliki seorang guru dalam melakukan pengajaran kepada peserta didiknya sehingga peserta didik dapat memahami materi pelajaran yang diajarkan. Keterampilan mengajar guru tidak boleh monoton, tetapi selalu memberikan suasana yang berbeda agar peserta didik tidak bosan dalam mengikuti kegiatan pembelajaran.

Dalam proses pembelajaran dalam kelas mahasiswa harus memiliki keterampilan mengajar yaitu dengan mampu membuka dan menutup pembelajaran dengan baik. Ada tiga tahapan dalam belajar yaitu kegiatan membuka, kegiatan inti dan kegiatan menutup. Pada kegiatan membuka seperti memberikan motivasi, memberitahukan tujuan pembelajaran dan mengondisikan kelas. Kegiatan inti seperti menggunakan bahasa yang baik, menggunakan model pembelajaran yang di tentukan, interaksi dalam belajar dan materi dengan jelas. Dan kegiatan menutup seperti memberikan tes, tugas rumah, menyimpulkan materi dan menyampaikan materi selanjutnya.

Dengan menguasai keterampilan mengajar, mahasiswa dapat melaksanakan tugasnya sebagai guru dalam mengembangkan potensi peserta didik agar dapat tercapainya tujuan pendidikan. Guru yang berkompeten akan lebih mampu menciptakan lingkungan belajar yang efektif dan mampu dalam pengelolaan kelasnya, sehingga hasil belajar siswa dapat tercapai secara optimal. Namun, permasalahan yang terjadi pada sebagian mahasiswa dalam keterampilan mengajar sangat beragam, misalnya seperti kurangnya mengelola kelas, tidak mampu menarik perhatian siswa, 
kurangnya variasi dalam mengajar, kurangnya interaksi mahasiswa dengan siswa, penggunaan media dan metode pembelajaran yang monoton, kurangnya kepercayaan diri dan memotivasi siswa dalam belajar. Kurangnya mempersiapkan rencana pembelajaran, kurangnya keterampilan bicara di ruang kelas sehingga menjadikan kendala dalam penyampaian materi pembelajaran.

Keterampilan mahasiswa dalam melaksanakan pembelajaran di PKM merupakan hasil dari seperangkat pengetahuan yang telah diberikan tentang bagaimana merencanakan pembelajaran, melaksanakan pembelajaran dan proses pembelajaran. Selama melaksanakan PKM mahasiswa sangat dituntut untuk menjadi seorang guru yang memiliki keterampilan mengajar, maka mahasiswa akan langsung terjun mengajar sendiri di kelas tanpa didampingi oleh guru pamong. Mahasiswa yang memiliki motivasi menjadi guru akan senang melaksakan kegiatan mengajar di sekolah dan mememiliki keterampilan pembelajaran dan mahasiswa yang kurang termotivasi akan melaksanakan progam PKM sebagai syarat kelulusan saja. Sehingga mahasiswa yang memiliki motivasi menjadi guru tinggi atau rendah dapat dilihat pada keterampilan mengajarnya di PKM. Oleh karena itu, motivasi yang berbeda-beda dalam diri manusia, maka dengan sendirinya timbul perbedaan dalam keterampilan mengajar mahasiswa PKM.

\section{METODE PENELETIAN}

Jenis desain penelitian ini termasuk dalam penelitian deskriptif korelatif. Menurut Arikunto (2010: 3) penelitian yang dilakukan untuk mengetahui tingkat hubungan antara dua variabel atau lebih, tanpa melakukan perubahan, tambahan atau manipulasi terhadap data yang sudah ada. Penelitian ini menggunakan pendekatan kuantitatif, yaitu dengan pengumpulan data menggunakan instrumen penelitian, analisis data bersifat kuantitatif/statistik dengan tujuan untuk menguji hipotesis yang telah ditetapkan (Sugiyono, 2011: 14). Penelitian ini ditujukan untuk menguji hipotesis yang telah diajukan dengan cara mencari besarnya hubungan variabel bebas terhadap variabel terikat.

Populasi dalam penelitian ini adalah mahasiswa Program Studi Teknik Elektro angkatan 2015 dan telah melaksanakan mata kuliah PKM.

\section{HASIL DAN PEMBAHASAN \\ Hasil Nilai Keterampilan Mengajar Mahasiswa PKM}

Berikut adalah distribusi frekuensi nilai keterampilan mengajar mahasiswa PKM yang dapat dilihat pada Tabel 4.1. dan Gambar 4.1.

Tabel 4.1. Distribusi Frekuensi Data Nilai Keterampilan Mengajar Mahasiswa PKM

\begin{tabular}{|c|c|c|c|}
\hline No & $\begin{array}{c}\text { Interval } \\
\text { Kelas }\end{array}$ & Tepi Kelas & $\mathrm{Fa}$ \\
\hline 1 & $\begin{array}{l}87,00- \\
88,42\end{array}$ & $\begin{array}{l}86,995- \\
88,425\end{array}$ & 4 \\
\hline 2 & $\begin{array}{c}88,43- \\
89,85\end{array}$ & $\begin{array}{c}88,425- \\
89,855\end{array}$ & 7 \\
\hline 3 & $\begin{array}{c}89,86- \\
91,28\end{array}$ & $\begin{array}{c}89,855- \\
91,285\end{array}$ & 8 \\
\hline 4 & $\begin{array}{c}91,29,- \\
92,71\end{array}$ & $\begin{array}{c}91,285- \\
92,715\end{array}$ & 13 \\
\hline 5 & $\begin{array}{c}92,72- \\
94,24\end{array}$ & $\begin{array}{c}92,715- \\
95,675\end{array}$ & 13 \\
\hline 6 & $\begin{array}{c}94,26- \\
95,67\end{array}$ & $\begin{array}{c}94,245- \\
91,115\end{array}$ & 13 \\
\hline 7 & $\begin{array}{c}95,68- \\
97,11 \\
\end{array}$ & $\begin{array}{c}95,675- \\
97,115 \\
\end{array}$ & 115 \\
\hline \multicolumn{3}{|c|}{ Jumlah } & 73 \\
\hline
\end{tabular}

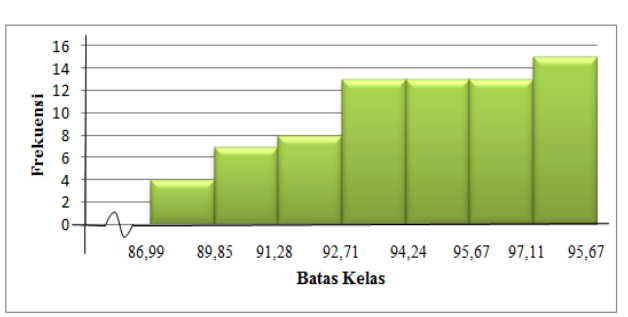

Gambar 4.1. Histrogram Nilai Keterampilan Mengajar Mahasiswa PKM

Berdasarkan histrogram di atas dapat terlihat bahwa frekuensi tertinggi berada pada kelas ke yaitu pada rentang nilai antara 95,68 sampai 97,11 yaitu sebanyak 15 orang mahasiswa atau $21 \%$ dari total sampel.

Berdasarkan tabel distribusi frekuensi Data Nilai Keterampilan Mengajar Mahasiswa PKM pada tabel 4.1. di atas dapat diketahui pada variabel terikat ini diperoleh frekuensi tertinggi berada pada rentang nilai antara 95,68 sampai 97,11 sebanyak 15 orang mahasiswa atau sebesar $21 \%$ dari total sampel. Sedangkan untuk frekuensi terendah 
berada pada rentang nilai antara 87 sampai 88,42 sebanyak 3 orang mahasiswa atau sebesar $5 \%$ dari total sampel. Kemudian untuk hasil lainnya yaitu sebanyak 7 orang memiliki nilai pada rentang antara 88,43 sampai 89,85 dengan frekuensi $10 \%$, hasil dengan 8 orang memiliki nilai pada rentang 89,86 sampai 91,28 dengan freskuensi $11 \%$ lalu pada 13 orang pada masing-masing rentang nilai yaitu 91, 29 sampai 92,71 dan 92,72 sampai 94,24 lalu 94,25 sampai 95,67 dengan frekuensi $18 \%$.

\section{Hasil Motivasi menjadi Guru}

Berikut adalah distribusi frekuensi kemampuan Praktik Keterampilan Mengajar (PKM) mahasiswa yang dapat dilihat pada Tabel 4.2. dan Gambar 4.2.

Tabel 4.2. Distribusi Frekuensi Data Motivasi menjadi Guru

\begin{tabular}{cccc}
\hline No & $\begin{array}{c}\text { Interval } \\
\text { Kelas }\end{array}$ & Tepi Kelas & Fa \\
\hline 1 & $86-94$ & $85,5-94,5$ & 5 \\
2 & $95-103$ & $94,5-103,5$ & 8 \\
3 & $104-112$ & $103,5-112,5$ & 15 \\
4 & $113-121$ & $112,5-121,5$ & 20 \\
5 & $122-130$ & $121,5-130,5$ & 11 \\
6 & $131-139$ & $130,5-139,5$ & 8 \\
7 & $140-148$ & $139,5-148,5$ & 6 \\
\hline \multicolumn{4}{c}{ Jumlah } \\
\hline
\end{tabular}

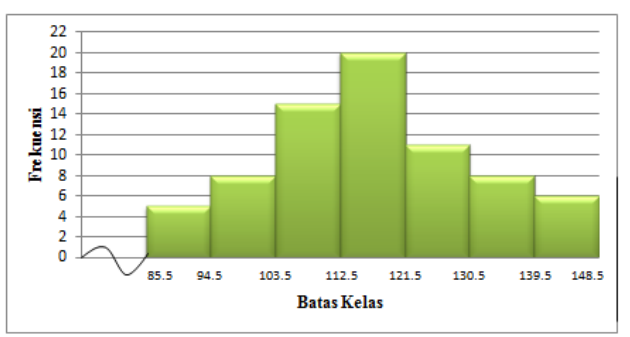

Gambar 4.2. Histrogram Motivasi menjadi Guru

Berdasarkan histrogram di atas dapat terlihat bahwa frekuensi tertinggi berada pada kelas ke 4 yaitu pada rentang nilai antara 113 sampai $121_{\mathrm{b}}$ yaitu sebanyak 20 orang mahasiswa atau $27 \%$ dari total sampel.

Berdasarkan tabel distribusi frekuensi Data Kemampuan Praktik Keterampilan Mengajar (PKM) Mahasiswa pada tabel 4.2 di atas dapat diketahui pada variabel terikat ini diperoleh frekuensi tertinggi berada pada rentang nilai antara 113 sampai 121 sebanyak 20 orang mahasiswa atau sebesar $27 \%$ dari total sampel. Sedangkan untuk frekuensi terendah berada pada rentang nilai antara 86 sampai 94 sebanyak
5 orang mahasiswa atau sebesar $7 \%$ dari total sampel. Kemudian untuk hasil lainnya yaitu sebanyak 8 orang memiliki nilai pada rentang masing-masing antara 95 sampai 103 dan 131sampai 139 sebesar $11 \%$ lalu 15 orang yang memiliki nilai pada rentang antara 104 sampai 112 dengan frekuensi $21 \%$ kemudian sebanyak 11 orang pada rentang nilai 122 sampai 130 atau $15 \%$ pada sebanyak 6 orang memiliki nilai pada rentang 140 sampai 148 dengan frekuensi $8 \%$.

\section{Uji Normalitas}

Berikut adalah perhitungan uji normalitas motivasi menjadi guru dan nilai keterampilan mengajar mahasiswa PKM yang dapat dilihat pada Tabel 4.3.

Tabel 4.3. Uji Normalitas Motivasi menjadi Guru dan Nilai Keterampilan Mengajar Mahasiswa PKM

\begin{tabular}{ccccc}
\hline & Dk & $\begin{array}{c}\boldsymbol{\chi 2}^{\mathbf{2}} \\
\text { Hitung }\end{array}$ & $\begin{array}{c}\boldsymbol{\chi 2}^{\mathbf{2}} \\
\text { Tabel }\end{array}$ & Ket \\
\hline $\begin{array}{c}\text { Motivasi } \\
\text { menjadi } \\
\text { Guru }\end{array}$ & 6 & 6,01 & 12,59 & Normal \\
$\begin{array}{c}\text { Nilai } \\
\text { Mahasiswa } \\
\text { PKM }\end{array}$ & 6 & 10,02 & 12,59 & Normal \\
\hline
\end{tabular}

a. Uji Normalitas Nilai Keterampialn Mengajar Mahasiswa PKM (Y)

Pada tabel 4.3. dapat diketahui normalitas pada penelitian ini dihitung dengan taraf signifikansi $\alpha=0,05$ denan hasil yaitu pada variabel nilai keterampilan mengajar mahasiswa PKM (Y) dengan nilai derajat kebebasan $(\mathrm{dk})=6$ diperoleh nilai $\chi 2$ hitung $=10,02$ sedangkan nilai $\chi 2$ tabel $=12,59$ karena $\chi 2$ hitung $<\chi 2$ tabel, berdasarkan hasil perhitungan dapat disimpulkan bahwa variabel nilai keterampilan mengajar mahasiswa PKM (Y) berdistribusi normal.

. Uji Normalitas Motivasi menjadi Guru (X)

Pada tabel 4.3. variabel motivasi menjadi guru (X) dihitung dengan taraf signifikansi $\alpha=0,05$ dengan nilai derajat kebebasan $(\mathrm{dk})=$ 6 mendapatkan hasil dengan nilai $\chi 2$ hitung= 6,01 sedangkan nilai $\chi 2$ tabel $=12,59$, berdasarkan hasil perhitungan dapat disimpulkan bahwa variabel motivasi menjadi guru (X) berdistribusi dengan normal karena $\chi 2$ hitung $<\chi 2$ tabel. 


\section{Uji Linieritas}

Berikut adalah perhitungan uji Linieritas motivasi menjadi guru dengan nilai keterampilan mengajar mahasiswa PKM yang dapat dilihat pada Tabel 4.4.

Tabel 4.4. Uji Linieritas Motivasi menjadi

Guru dengan Nilai Keterampilan Mengajar Mahasiswa PKM

\begin{tabular}{cccccc}
\hline Uji & \multirow{2}{*}{$\mathrm{n}$} & $\mathrm{dk}$ & $\begin{array}{c}\mathrm{F} \\
\text { hitung }\end{array}$ & $\begin{array}{c}\mathrm{F} \\
\text { Tabel }\end{array}$ & Ket \\
\hline $\begin{array}{c}\text { Linieritas } \\
\text { Motivasi }\end{array}$ & & & & & \\
menjadi & & & & & \\
$\begin{array}{c}\text { Guru dan } \\
\text { Nilai }\end{array}$ & 73 & 33 & 0,4897 & 1,74 & Linier \\
Mahasiswa & & & & & \\
PKM & & & & & \\
\hline
\end{tabular}

Berdasarkan tabel 4.4. Hasil pengujian linieritas di atas, diketahui bahwa nilai $\mathrm{F}_{\text {hitung }}=$ 0,4897 dengan derajat kebebasan penyebut 33 dan derajat kebebasan pembilang 38 dan taraf signifikansi $\alpha=5 \%$ dengan nilai $\mathrm{F}_{\text {tabel }}=1,74$. Sesuai dengan kriteria yang sudah dijelaskan di atas, dapat disimpulkan bahwa penelitian ini bersifat linier karena perhitungan linieritas menunjukkan nilai $F_{\text {hitung }}<\mathrm{F}_{\text {tabel}}$, maka $\mathrm{H}_{0}$ diterima yang berarti terdapat persamaan linier antara variabel motivasi menjadi guru dengan nilai keterampilan mengajar mahasiswa PKM.

\section{Uji Hipotesis}

Berikut adalah perhitungan uji Hipotesis korelasi pearson product moment motivasi menjadi guru dengan nilai keterampilan mengajar mahasiswa PKM dapat dilihat pada Tabel 4.5. dan Tabel 4.6. untuk Uji Signifikansi Korelasi

Tabel 4.5. Uji Korelasi Pearson Product Moment

\begin{tabular}{ccccc}
\hline Dk & $\boldsymbol{\alpha}$ & r Hitung & r Tabel & Ket \\
\hline 73 & 0,05 & 0,4685 & 0,2303 & $\begin{array}{c}\text { Ha } \\
\text { diterima }\end{array}$ \\
\hline
\end{tabular}

Tabel 4.6. Uji Signifikansi Korelasi (uji t)

\begin{tabular}{ccccc}
\hline Dk & $\boldsymbol{\alpha}$ & t Hitung & t Tabel & Ket \\
\hline 73 & 0,05 & 4,04652 & 1,99394 & $\begin{array}{c}\text { Ha } \\
\text { diterima }\end{array}$ \\
\hline
\end{tabular}

Berdasarkan hasil pengujian hipotsesis pada tabel 4.5. menggunakan korelasi Product Moment diketahui bahwa nilai $\mathrm{r}_{\mathrm{xy}}=0,4685$ dengan derajat kebebasan sebesar 71 dan taraf signifikansi $\alpha=5 \%$. Jadi, hasil menunjukan bahwa terdapat hubungan antara $\mathrm{X}$ dan $\mathrm{Y}$ atau motivasi menjadi guru dengan nilia keterampilan mengajar mahasiswa PKM.

Selanjutnya tingkat hubungan antara motivasi menjadi guru dengan kemampuan Praktik Keterampilan Mengajar (PKM) mahasiswa menunjukan nilai $\mathrm{r}_{\text {hitung }}=0,4685$ berada pada nilai interval koesifien korelasi 0,40 - 0,599 maka tingkat hubungan sedang.

Setelah melakukan uji korelasi, tahap selanjutnya adalah menguji signifikansi pada tabel 4.6. koefisien korelasi menggunakan rumus uji-t. Dengan menggunakan perhitungan pada taraf sigifikansi 5\% dengan derajat kebebasan sebesar 71 maka didapat hasil $t_{\text {tabel }}=1,993$ dengan kriteria pengujian sebagai berikut: berdasarkan hasil pengujian signifikansi koefisien korelasi didapat nilai $t_{\text {hitung }}=4,04652$ dan $t_{\text {tabel }}=1,998$ dimana $\mathrm{H}_{0}$ ditolak dan dapat disimpulkan bahwa terdapat hubungan yang signifikan antara motivasi menjadi guru dengan nilai keterampilan mengajar mahasiswa PKM.

Langkah selanjutnya adalah menentukan nilai koefisien determinasinya, dimana nilai koefisien determinasi ini adalah kuadrad dari nilai koefisien korelasi $\left(r^{2}\right)$ untuk koefisien penentu, karena varians yang terjadi pada variabel dependen dapat dijelaskan melalui varians yang terjadi pada variabel independen. Dari perhitungan yang telah dilakukan didapat $r=0,4685$ maka nilai koefisien determinasinya $\left(r^{2}\right)=0,2195$. Dapat dikatakan bahwa varians yang terjadi pada variabel motivasi menjadi sebesar $22 \%$ mempengaruhi terhadap nilai keterampilan mengajar mahasiswa PKM dan sisanya 78\% dipengaruhi oleh faktor lain.

\section{KESIMPULAN DAN SARAN Kesimpulan}

Berdasarkan hasil penelitian dan pengolahan data yang telah dilakukan dapat disimpulkan sebagai berikut: Terdapat hubungan yang positif dan signifikan antara motivasi menjadi guru dengan nilai keterampilan mengajar mahasiswa PKM. Dengan ditunjukkan hasil perhitungan pada uji korelasi menggunakan uji-r diketahui nilai rhitung $=0,4685$ dengan rtabel $=0,203$. Dimana dari kriteria pengujian yang digunakan pada penelitian ini, terdapat hasil pengujian hipotesis tersebut menunjukkan maka H0 ditolak dan $\mathrm{Ha}$ diterima. 
Selanjutnya peneliti melakukan uji signifikansi dengan uji-t dan mendapatkan hasil thitung sebesar $=0,04652$, dan tabel sebesar $=1,998$ dimana thitung > ttabel yang berarti $\mathrm{H} 0$ ditolak dan artinya mempunyai hubungan positif dan signifikan, maka dapat disimpulkan bahwa terdapat hubungan yang signifikan antara motivasi menjadi guru dengan nilai keterampilan mengajar mahasiswa PKM.

\section{Saran}

Saran untuk penelitian selanjutnya, penelitian ini sebaiknya dikembangkan modelmodel pembelajaran yang terkait dengan penggerak/pendorong aktifitas yang menyenangkan mahasiswa sebagai calon guru serta mampu menyediakan sarana dan prasarana sebagai suatu wadah untuk meningkatkan motivasi menjadi guru. Selanjutnya penelitian ini memberikan sumbangan kepada kurikulum, materi ajar dan bahan penelitian untuk mahasiswa.

\section{DAFTAR PUSTAKA}

Anggareni, Neni. 2008. Hubungan motivasi menjadi guru dengan hasil belajar PPL pada Mahasiswa Pendidikan Akutansi.[Skripsi]. Jakarta: Universitas Negeri Jakarta.

Djamarah, Syaiful Bahri. 2011. Psikologi Belajar. Jakarta: Rineka Cipta.

Eurika, Novy. 2016. Kemampuan praktik mengajar mahasiswa PPL Prodi Pendidikan Biologi UNMUH. [E-jurnal]. Jember: $\quad$ FKIP, Universitas Muhammadiyah Jember.

Hamzah, Uno. 2007. Teori Motivasi dan Pengukurannya: Analisis di Bidang Pendidikan.

Hamzah, Uno. 2011. Motivasi Psikologi Pendidikan. Jakarta: Bumi Aksara.

Kusnadi. 2008. Strategi Pembelajaran Ilmu Pengetahuan. Pekan Baru: Yayasan Pusaka Riau.

MenkumHAM. 2005. Undang- Undang Republik Indonesia No. 14 Tahun 2005 tentang Guru dan Dosen. Jakarta: Kementrian Hukum dan HAM.

Rusman. 2011. Model-Model Pembelajaran: Mengembangkan Profesionalisme Guru. Cet. III. Jakarta: Raja Grafindo Persada.

Sami'an dan Premana, Analya. 2013/2014. Hubungan Antara Peran Guru Pamong dan Minat Mahasiswa Menjadi Guru dengan Prestasi Program Pengalaman Lapangan (PPL) Progdi Pendidikan Ekonomi Akuntansi Angkatan 2010 FKIP Universitas Muhammdiyh Surakarta Tahun Ajaran 2013/2014. [E-jurnal]. Surakarta: FKIP, Universitas Muhammadiyah Surakarta.

Saragih, A. Hasan. 2008. Jurnal Tabularasa Pps Unimed. Vol.5 No.1.

Sholihin, Ahmad. 2014. Keterampilan yang Harus Dimiliki Guru dalam Mengajar. [Diakses pada 11 Agustus 2019].

Siregar, Eveline. Nara, Hartini. 2014. Teori Belajar dan Pembelajaran. Bogor: Ghalia Indonesia.

Sugiyono. 2010. Metode Penelitian Pendidikan. Bandung: ALFABETA.

Sugiyono. 2011. Metode Penelitian Kuantitatif, Kualitatif dan $R \& D$. Bandung: Alfabeta.

Suparman. 2010. Gaya Mengajar yang Menyenangkan Siswa. Yogyakarta: Pinus Book Publisher.

Tim Penyusun. 2017. Buku Pedoman PKM. Jakarta: Pusat PPL/PKL Universitas Negeri Jakarta.

Zakky. 2014. Pengertian Nilai Menurut Para Ahli dan Secara Umum https://www.zonareferensi.com/penger tian-nilai/. [Diakses pada 11 Agustus 2019]. 